\title{
Influence of alloying additions (Mo, Mn, Co) on the magnetic properties of $\mathrm{FeSiB}$ amorphous alloys
}

\author{
Łukasz MADEJ ${ }^{1}$, Lidiya BEDNARSKA ${ }^{2}$, Viktor NOSENKO ${ }^{3}$, Bogdan KOTUR ${ }^{2}$, Artur CHROBAK ${ }^{4}$, \\ Grzegorz HANECZOK ${ }^{1}$
}

${ }^{1}$ Institute of Materials Science, University of Silesia, Bankowa 12, 40-007 Katowice, Poland

${ }^{2}$ Ivan Franko National University of Lviv, Kyryla and Mefodiya St. 6, 79005 Lviv, Ukraine

${ }^{3}$ Institute for Metal Physics of the NAS Ukraine, Vernadsky Av. 36, 03680 Kyiv, Ukraine

${ }^{4}$ Institute of Physics, University of Silesia, Uniwersytecka 4, 40-007 Katowice, Poland

*Corresponding author.E-mail: Imadej@us.edu.pl

Received October 24, 2008; accepted December 29, 2008; available on-line March 19, 2009

In the present paper the magnetic permeability $\mu$, magnetic after-effects $\Delta \mu / \mu$, saturation magnetization $\mu_{0} M_{\mathrm{S}}$, Curie temperature $T_{\mathrm{C}}$, primary crystallization temperature $T_{\mathrm{X} 1}$ and magnetostriction coefficients $\lambda$ were examined for a group of amorphous alloys, i.e. $\mathrm{Fe}_{80} \mathrm{Si}_{6} \mathbf{B}_{14}$ and $\mathrm{Fe}_{75} \mathrm{XSi}_{6} \mathbf{B}_{14}\left(\mathrm{X}=\mathrm{Mo}_{5}, \mathrm{Mo}_{2.5} \mathrm{Mn}_{2.5}, \mathrm{Mo}_{2.5} \mathrm{Co}_{2.5}\right)$. It was shown that these alloying additions cause a decrease of the Curie temperature, saturation magnetization, magnetic permeability, magnetic after-effects and magnetostriction coefficients, and an increase of the primary crystallization temperature with respect to $\mathrm{Fe}_{80} \mathrm{Si}_{6} \mathrm{~B}_{14}$. The observed decrease of both magnetostriction coefficients - saturation magnetostriction and volume magnetostriction, is correlated with the decrease of the Curie temperature. Cobalt and manganese atoms influence the crystallization temperature in the same way as molybdenum, which means that the diffusion processes responsible for crystallization are not enough sensitive to this kind of alloying addition.

Amorphous alloys / Magnetic properties / Magnetostriction

\section{Introduction}

Iron-based amorphous alloys obtained by melt spinning technique in the form of thin ribbons, are very interesting soft magnetic materials. Many properties of these materials are superior to those of conventional materials with the same chemical composition [1]. For example, for finemet (Fe-X-Si-B$\mathrm{Cu}$, where $\mathrm{X}$ are alloying additions) and nanoperm (Fe-X-B, Fe-X-B-Cu) type alloys, the magnetic permeability in weak magnetic fields can be of the order of $10^{4}$ and the coercive field below $1 \mathrm{~A} / \mathrm{m}$. The nanoperm alloys show higher values of saturation magnetization (1-1.5 T) and relatively low Curie temperatures (300-400 K). A partial substitution of Co atoms for $\mathrm{Fe}$ (the so-called hitperm type alloys $\mathrm{Fe}-\mathrm{Co}-\mathrm{X}-\mathrm{B}-\mathrm{Cu}$ ) causes an increase of the Curie temperature $(>600 \mathrm{~K})$ and saturation magnetization. Unfortunately, it also causes a decrease of the magnetic permeability.

It is already known that the magnetostriction coefficients of amorphous alloys based on iron are higher than for nickel- or cobalt-based alloys [2,3]. In general, the magnetic properties strongly depend on the chemical composition of this kind of alloy. Even small amounts of alloying additions can drastically change the magnetic properties, the course of the structural relaxation and crystallization processes. Therefore the aim of the present paper was to study the influence of alloying additions Mo, MoMn, and MoCo to amorphous alloys $\mathrm{FeXSiB}$ on the magnetic properties - magnetostriction, magnetic permeability, magnetic after-effects, saturation magnetization, Curie temperature, and also the crystallization temperature, as crystallization (nanocrystallization) strongly influences the magnetic properties. In the present paper the crystallization phenomenon itself was not examined because for this kind of amorphous alloy it is well established that the primary crystallization (nanocrystallization) leads to the formation of alpha iron nanograins embedded in the amorphous matrix (for details see $[4,5]$ ).

\section{Experimental procedure and results}

Experiments were carried out for amorphous alloys $\mathrm{Fe}_{80} \mathrm{Si}_{6} \mathrm{~B}_{14}, \mathrm{Fe}_{75} \mathrm{Mo}_{5} \mathrm{Si}_{6} \mathrm{~B}_{14}, \mathrm{Fe}_{75} \mathrm{Mo}_{2.5} \mathrm{Co}_{2.5} \mathrm{Si}_{6} \mathrm{~B}_{14}$ and $\mathrm{Fe}_{75} \mathrm{Mo}_{2.5} \mathrm{Mn}_{2.5} \mathrm{Si}_{6} \mathrm{~B}_{14}$, obtained by the melt spinning technique (rapid cooling from the liquid phase with 
cooling rates of the order of $10^{7} \mathrm{~K} / \mathrm{s}$ ) in the form of strips of thickness and width of about $25-30 \mu \mathrm{m}$ and 8-10 mm, respectively. For the as quenched samples the following magnetic properties were measured: i) magnetic permeability $\mu$ (Maxwell-Wien bridge, frequency about $1030 \mathrm{~Hz}$ and magnetic field $H=0.5 \mathrm{~A} / \mathrm{m}$ ), ii) magnetic after-effects $\Delta \mu / \mu$ (where $\Delta \mu$ is the difference between the magnetic permeability determined at time $t_{1}=30 \mathrm{~s}$ and $t_{2}=1800 \mathrm{~s}$ after demagnetization), iii) magnetization in saturation $\mu_{0} M_{\mathrm{S}}$, the Curie temperature $T_{\mathrm{C}}$, the primary crystallization temperature $T_{\mathrm{X} 1}$ (magnetic balance, field $0.4 \mathrm{~T}$ ) and iv) magnetostriction coefficients $\lambda$ (infra-red magneto-dilatometer).

Magnetostriction, defined as any change in the dimensions of a magnetic body caused by a change in its magnetic state [6], was determined based on the following expression [6-8]:

$$
\lambda=\frac{\Delta l}{l}=\frac{1}{3} \omega+\frac{3}{2} \lambda_{S}\left(\cos ^{2} \Theta-\frac{1}{3}\right)
$$

where: $l$ is the sample length, $\theta$ is the angle between the directions of magnetization and strain measurement, $\omega$ is the so-called volume magnetostriction (isotropic), and $\lambda_{\mathrm{S}}$ is the saturation magnetostriction (anisotropic). The magnetostriction coefficients $\omega$ and $\lambda_{\mathrm{s}}$ were determined by measuring successively the strain observed with a magnetic field applied parallel $\left(\lambda_{\|}\right)$and perpendicular $\left(\lambda_{\perp}\right)$ to the direction of the strain measurement. It may be noticed that from equation (1) for $\theta=0$ one can get $\lambda=\lambda_{\|}$and for $\theta=\pi / 2, \lambda=\lambda_{\perp}$. According to the above remarks the saturation magnetostriction $\lambda_{\mathrm{S}}$ can be expressed by:

$\lambda_{S}=\frac{2}{3}\left(\lambda_{\|}-\lambda_{\perp}\right)$

and the volume magnetostriction $\omega$, defined as $\Delta V / V$ (where $V$ is the sample volume), is:

$\omega=\lambda_{\|}+2 \cdot \lambda_{\perp}$

For all the examined alloys the magnetostriction coefficients $\lambda_{\|}$and $\lambda_{\perp}$ were determined versus the magnetic field for samples of $5 \mathrm{~cm}$ length. The results are shown in Figs. 1 and 2. It can be seen that in all cases the magnetostriction coefficients increase with increasing magnetic field and show saturation behaviour (see [9-13]). The influence of the alloying additions on the magnetostriction is well seen.

Fig. 3 shows the saturation magnetization $\mu_{0} M_{\mathrm{S}}$ versus temperature for the $\mathrm{Fe}_{80} \mathrm{Si}_{6} \mathrm{~B}_{14}, \mathrm{Fe}_{75} \mathrm{Mo}_{5} \mathrm{Si}_{6} \mathrm{~B}_{14}$, and $\mathrm{Fe}_{75} \mathrm{Mo}_{2.5} \mathrm{Mn}_{2.5} \mathrm{Si}_{6} \mathrm{~B}_{14}$ alloys. In all cases the measured magnetization decreases with increasing temperature up to the Curie point of the amorphous phase. Above the Curie temperature the examined materials are in the paramagnetic state and magnetization is almost zero. At higher temperatures an increase of the magnetization due to the formation of a new ferromagnetic phase (nanocrystallization) is observed. It is clear that an increase of the molybdenum content causes a decrease of the saturation magnetization and a shift of the nanocrystallization to higher temperatures. The replacement of $5 \%$ of iron by molybdenum atoms in the $\mathrm{Fe}_{80} \mathrm{Si}_{6} \mathrm{~B}_{14}$ alloy causes a decrease of $\mu_{0} M_{\mathrm{S}}$ from $1570 \mathrm{mT}$ to $940 \mathrm{mT}$.

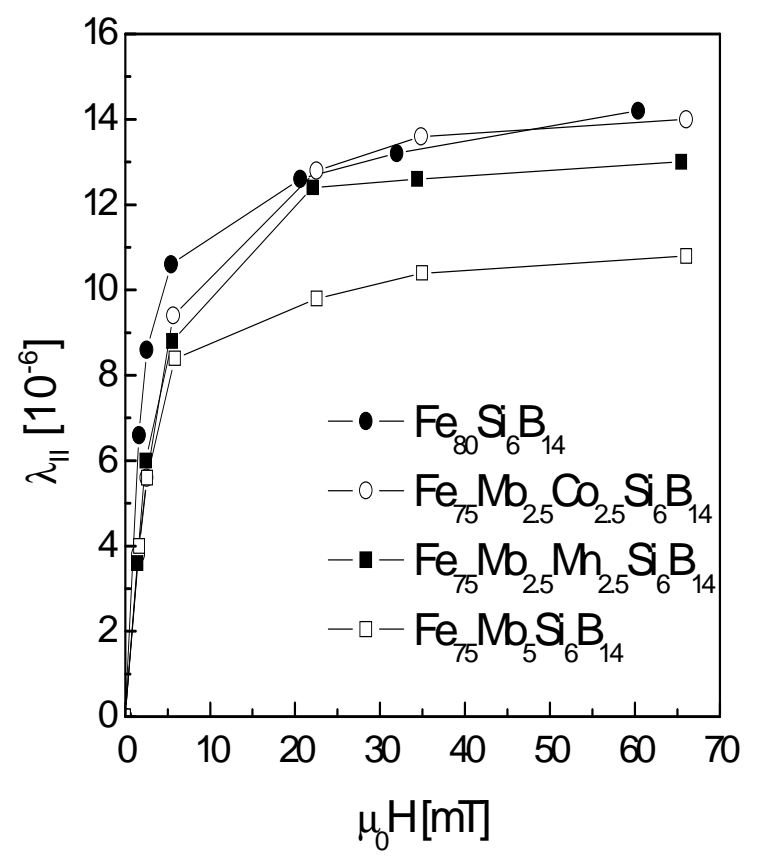

Fig. 1 Magnetostriction coefficient $\lambda_{\|}$versus magnetic field $\mu_{0} H$ for all the examined alloys.

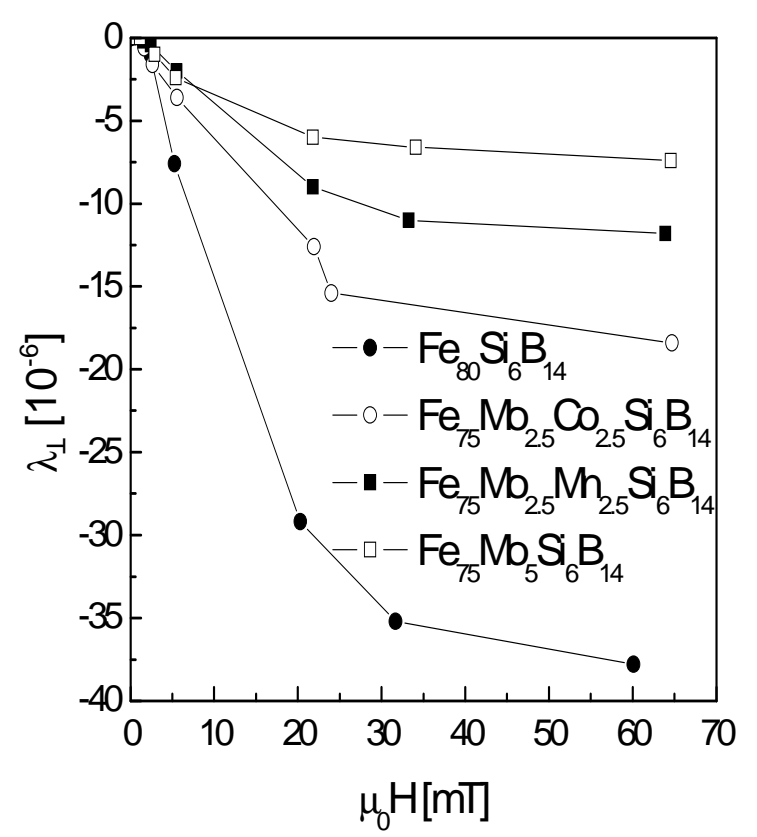

Fig. 2 Magnetostriction coefficient $\lambda_{\perp}$ versus magnetic field $\mu_{0} H$ for all the examined alloys. 


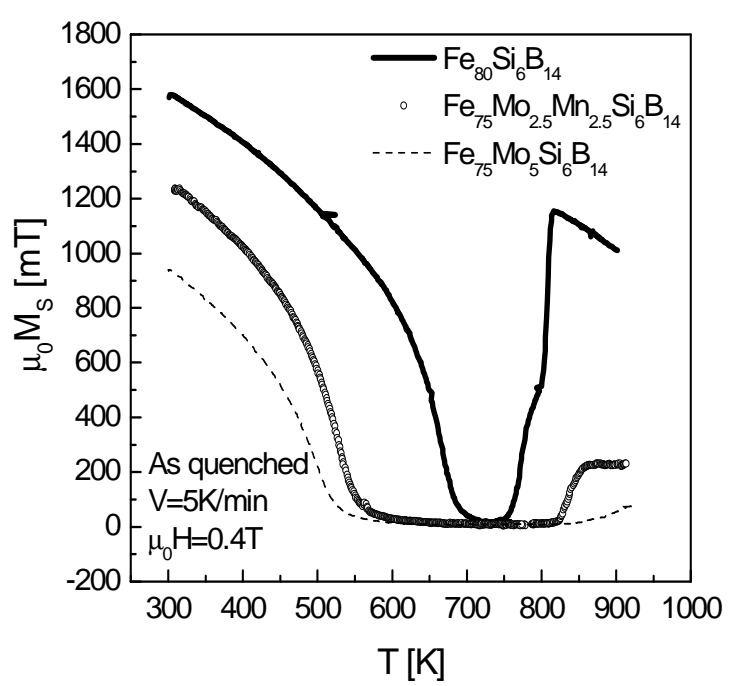

Fig. 3 Saturation magnetization $\mu_{0} M_{\mathrm{S}}$ versus temperature $T$ for some of the examined alloys (heating rate $5 \mathrm{~K} / \mathrm{min}$ ).

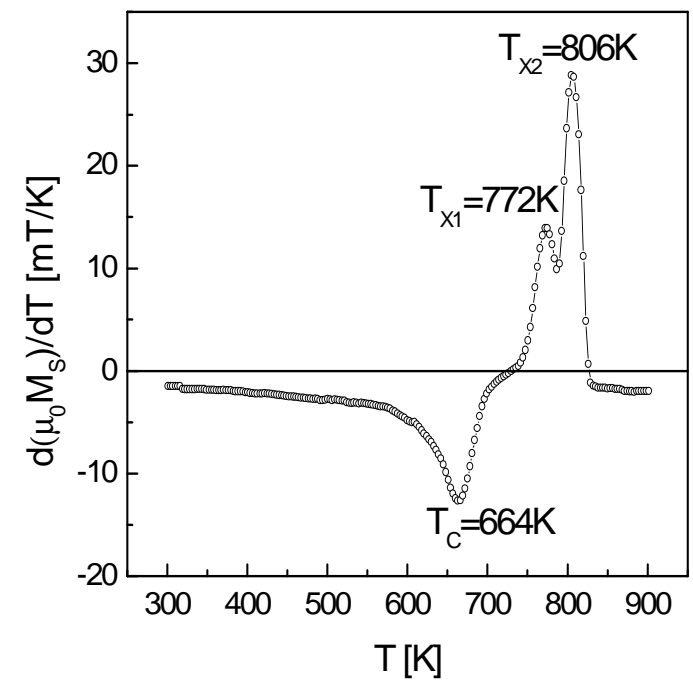

Fig. $4 \mathrm{~d}\left(\mu_{0} M_{\mathrm{S}}\right) / \mathrm{d} T$ (see the data of Fig. 3) versus temperature $T$ for the $\mathrm{Fe}_{80} \mathrm{Si}_{6} \mathrm{~B}_{14}$ alloy (heating rate $5 \mathrm{~K} / \mathrm{min}$ ).

The Curie temperature and the crystallization temperatures were determined as the position of the corresponding inflection point of the $\mu_{0} M_{\mathrm{S}}(T)$ curve (minima or maxima in the $\mathrm{d}\left(\mu_{0} M_{\mathrm{S}}\right) / \mathrm{d} T$ curve). The $\mathrm{d}\left(\mu_{0} M_{\mathrm{S}}\right) / \mathrm{d} T$ curve for the $\mathrm{Fe}_{80} \mathrm{Si}_{6} \mathrm{~B}_{14}$ alloy is shown in Fig. 4. An increase of the molybdenum content causes a decrease of the Curie temperature and an increase of the primary crystallization temperature from $664 \mathrm{~K}$ to $495 \mathrm{~K}$ and from $772 \mathrm{~K}$ to $898 \mathrm{~K}$ for the $\mathrm{Fe}_{80} \mathrm{Si}_{6} \mathrm{~B}_{14}$ and $\mathrm{Fe}_{75} \mathrm{Mo}_{5} \mathrm{Si}_{6} \mathrm{~B}_{14}$ alloys, respectively. It should be mentioned that for the $\mathrm{Fe}_{80} \mathrm{Si}_{6} \mathrm{~B}_{14}$ alloy two stages of crystallization were observed, i.e. the primary crystallization (maximum of the $\mathrm{d}\left(\mu_{0} M_{\mathrm{S}}\right) / \mathrm{d} T$ curve at $772 \mathrm{~K}$, heating rate $5 \mathrm{~K} / \mathrm{min}$ ) and the secondary crystallization (maximum of the $\mathrm{d}\left(\mu_{0} M_{\mathrm{S}}\right) / \mathrm{d} T$ curve at $806 \mathrm{~K}$, heating rate $5 \mathrm{~K} / \mathrm{min}$.). For the other alloys these two stages are apparently close to each other and only one peak in $\mathrm{d}\left(\mu_{0} M_{\mathrm{S}}\right) / \mathrm{d} T$ was observed. A detailed examination of the crystallization phenomenon by applying DSC and magnetic methods are discussed in [5] (e.g. see Fig. 3 in [5]). The magnetic permeability $\mu$ was determined for all the examined alloys at room temperature in a field of $0.5 \mathrm{~A} / \mathrm{m}$. An increase of the molybdenum content causes a decrease of the magnetic permeability. It was found that the replacement of $5 \%$ of the iron by molybdenum atoms in the $\mathrm{Fe}_{80} \mathrm{Si}_{6} \mathrm{~B}_{14}$ alloy causes a decrease of $\mu$ from 1500 to 600 .

It may be added that it is generally accepted that in ferromagnetic amorphous alloys the intensity of the magnetic after-effects $\Delta \mu / \mu$ is proportional to the free volume content [4]. The highest value of $\Delta \mu / \mu$ (18.8\%) was obtained for the $\mathrm{Fe}_{80} \mathrm{Si}_{6} \mathrm{~B}_{14}$ alloy and the lowest value (9.3\%) for the $\mathrm{Fe}_{75} \mathrm{Mo}_{2.5} \mathrm{Mn}_{2.5} \mathrm{Si}_{6} \mathrm{~B}_{14}$ alloy, which indicates that the highest free volume content is observed for the base alloy.

\section{Discussion}

The magnetic parameters of the alloys examined in the present paper (the Curie temperature $T_{\mathrm{C}}$, primary crystallization temperature $T_{\mathrm{X} 1}, \quad$ saturation magnetization $\mu_{0} M_{\mathrm{S}}$, magnetic permeability $\mu$, magnetic after-effect $\Delta \mu / \mu$, magnetostriction coefficients $\lambda_{\|}, \lambda_{\perp}$, saturation magnetostriction $\lambda_{\mathrm{S}}$ (calculated according to equation (2)) and volume magnetostriction coefficient $\omega$ (calculated according to equation (3)) are listed in Table 1.

From this Table and Figs. 1 and 2 it is readily seen that all the examined alloying additions cause a decrease of the magnetostriction coefficients. The replacement of $5 \%$ of iron by molybdenum in the $\mathrm{Fe}_{80} \mathrm{Si}_{6} \mathrm{~B}_{14}$ alloy causes a decrease of $\lambda_{\|}$(positive) and $\lambda_{\perp}$ (negative) by about $24 \%$ and $80 \%$, respectively. It seems that such a change of the magnetostriction with respect to the base alloy can be explained by a change of the elastic properties, caused by molybdenum. The atomic radius of molybdenum is larger than the atomic radius of iron $(190 \mathrm{pm}$ and $156 \mathrm{pm}$, respectively [14]), which means that the Mo atoms in the amorphous structure cause an increase of the inter-atomic distances and consequently a decrease of Young's modulus and the magnetoelastic energy.

The data presented in Table 1 also shows that the decrease of the magnetostriction coefficients $\lambda_{\mathrm{S}}$ and $\omega$ in the examined alloys is correlated with the observed decrease of the Curie temperature $T_{\mathrm{C}}$. This correlation is demonstrated in Figs. 5 and 6. It seems that such a linear dependence can be explained as an effect of the weakening of the magneto-elastic coupling due to the shift of the Curie temperature closer to the temperature of the measurements (room temperature). Indeed, the examined alloying additions cause a decrease of the Curie temperature and at the same time a weakening of the magneto-elastic coupling.

This conclusion is confirmed by the fact that the increase of the molybdenum content in the examined 
Table 1 Curie temperature $T_{\mathrm{C}}$, primary crystallization temperature $T_{\mathrm{X} 1}$, saturation magnetization $\mu_{0} M_{\mathrm{S}}$, magnetic permeability $\mu$, magnetostriction coefficients $\lambda_{\|}, \lambda_{\perp}$, saturation magnetostriction $\lambda_{\mathrm{S}}$, and volume magnetostriction coefficient $\omega$ for the examined alloys.

\begin{tabular}{l|c|c|c|c|c|c|c|c|cc}
\hline Alloy & $\begin{array}{c}T_{\mathrm{C}} \\
{[\mathrm{K}]}\end{array}$ & $\begin{array}{c}T_{\mathrm{X} 1} \\
{[\mathrm{~K}]}\end{array}$ & $\begin{array}{c}\mu_{0} M_{\mathrm{S}} \\
{[\mathrm{mT}]}\end{array}$ & $\mu$ & $\begin{array}{c}\Delta \mu / \mu \\
{[\%]}\end{array}$ & $\begin{array}{c}\lambda_{\|} \\
{\left[10^{-6}\right]}\end{array}$ & $\begin{array}{c}\lambda_{\perp} \\
{\left[10^{-6}\right]}\end{array}$ & $\begin{array}{c}\lambda_{\mathrm{S}} \\
{\left[10^{-6}\right]}\end{array}$ & $\begin{array}{c}\omega \\
{\left[10^{-6}\right]}\end{array}$ \\
\hline $\mathrm{Fe}_{80} \mathrm{Si}_{6} \mathrm{~B}_{14}$ & 664 & 772 & 1570 & 1520 & 18.2 & 14.2 & -37.8 & 34.7 & -61.4 \\
$\mathrm{Fe}_{75} \mathrm{Mo}_{5} \mathrm{Si}_{6} \mathrm{~B}_{14}$ & 495 & 898 & 940 & 600 & 13.3 & 10.8 & -7.4 & 12.1 & -4 \\
$\mathrm{Fe}_{75} \mathrm{Mo}_{2.5} \mathrm{Co}_{2.5} \mathrm{Si}_{6} \mathrm{~B}_{14}$ & 611 & 836 & 1030 & 690 & 16.4 & 14 & -17.2 & 21.6 & -22.8 \\
$\mathrm{Fe}_{75} \mathrm{Mo}_{2.5} \mathrm{Mn}_{2.5} \mathrm{Si}_{6} \mathrm{~B}_{14}$ & 527 & 837 & 1240 & 1360 & 9.3 & 13 & -11.8 & 16.5 & -10.6 \\
\hline
\end{tabular}

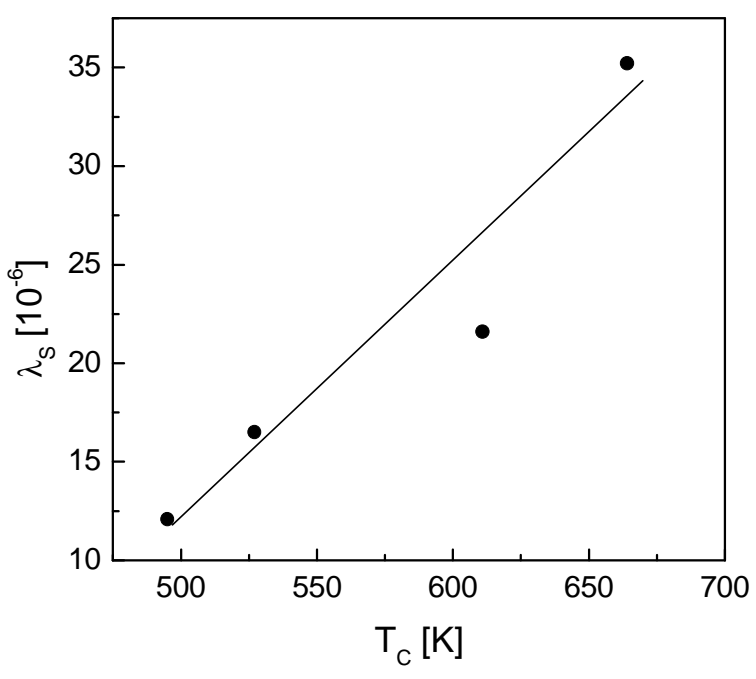

Fig. 5 Saturation magnetostriction coefficient $\lambda_{\mathrm{S}}$ versus the Curie temperature $T_{\mathrm{C}}$ for all the examined alloys.

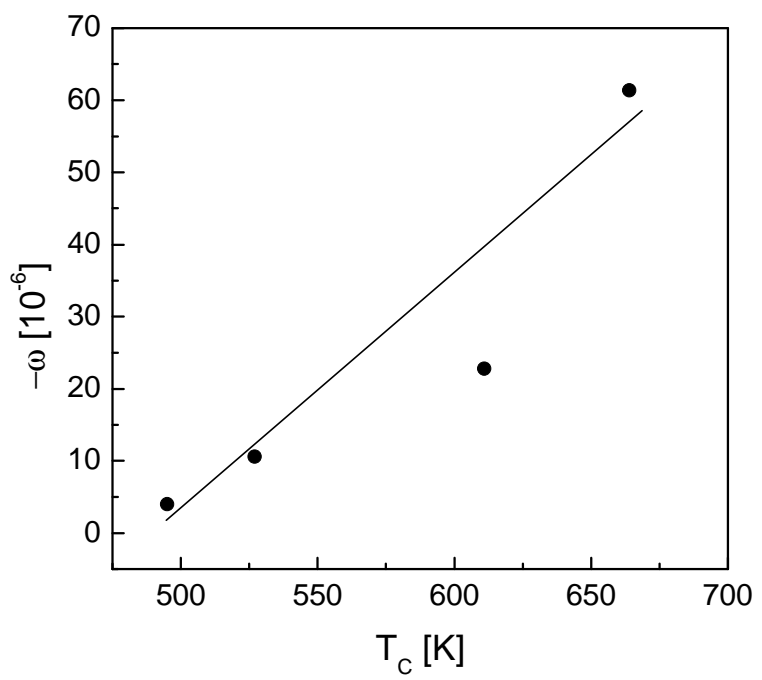

Fig. 6 Volume magnetostriction coefficient $\omega$ versus the Curie temperature $T_{\mathrm{C}}$ for all the examined alloys.

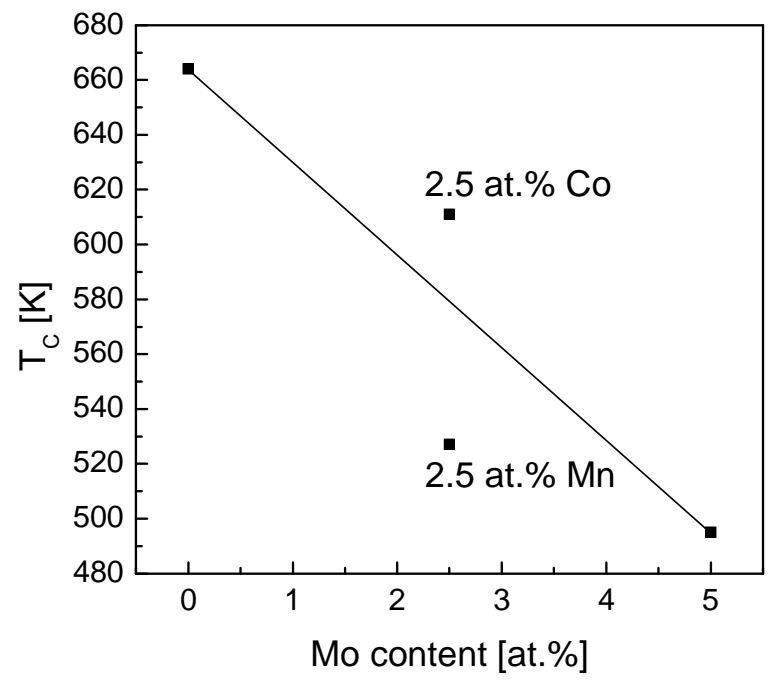

Fig. 7 Curie temperature $T_{\mathrm{C}}$ versus the molybdenum content for some of the examined alloys.

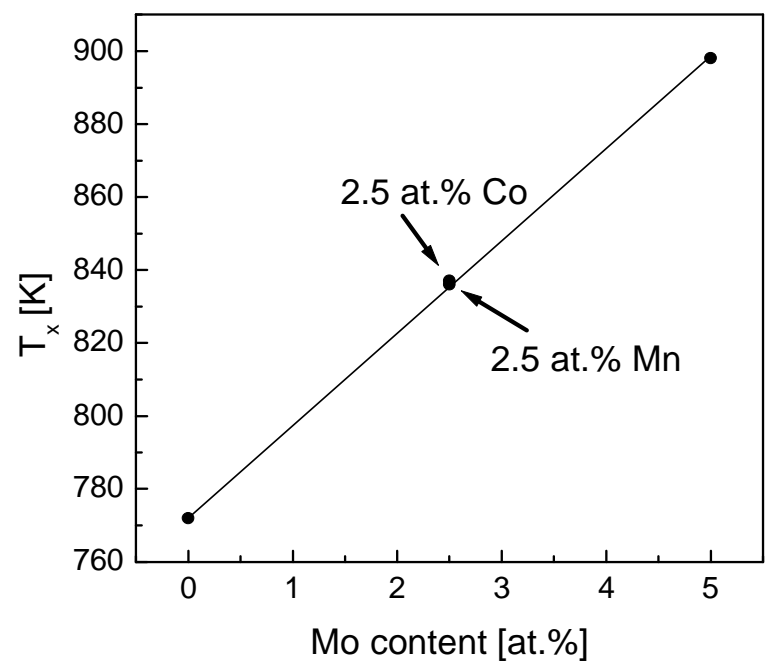

Fig. 8 Crystallization temperature $\mathrm{T}_{\mathrm{x}}$ versus the molybdenum content for some of the examined alloys. 
alloys also causes a decrease of the saturation magnetization (see Fig. 3) and magnetic permeability in the following sequence: $\mathrm{Fe}_{80} \mathrm{Si}_{6} \mathrm{~B}_{14}$, $\mathrm{Fe}_{75} \mathrm{Mo}_{2.5} \mathrm{Mn}_{2.5} \mathrm{Si}_{6} \mathrm{~B}_{14}, \quad \mathrm{Fe}_{75} \mathrm{Mo}_{2.5} \mathrm{Co}_{2.5} \mathrm{Si}_{6} \mathrm{~B}_{14}$, and $\mathrm{Fe}_{75} \mathrm{Mo}_{5} \mathrm{Si}_{6} \mathrm{~B}_{14}$.

Figs. 7 and 8 show the Curie temperature and the crystallization temperature plotted versus the molybdenum content for the examined alloys. It can be seen that cobalt causes an increase of the Curie temperature of about $5 \%$, and manganese causes a decrease of about $9 \%$ with respect to the expected value for 2.5 at.\% Mo. From Fig. 8 it can be seen that both cobalt and manganese influence the crystallization temperature in the same way as molybdenum. It means that the diffusion processes responsible for crystallization are not enough sensitive to this kind of alloying addition.

\section{Conclusions}

The main conclusions of the present paper can be summarized as follows:

- Alloying additions of Mo, MoMn, and MoCo to the base alloy $\mathrm{Fe}_{80} \mathrm{Si}_{6} \mathrm{~B}_{14}$ cause a decrease of the Curie temperature, saturation magnetization, magnetic permeability, magnetic after-effects and magnetostriction coefficients, and an increase of the primary crystallization temperature.

- The observed decrease of both magnetostriction coefficients - saturation magnetostriction and volume magnetostriction, is correlated with a decrease of the Curie temperature.

- Co and Mn atoms influence the crystallization temperature in the same way as molybdenum, which means that the diffusion processes responsible for crystallization are not enough sensitive to this kind of alloying addition.

\section{References}

[1] M.E. McHenry, M.A. Willard, D. Laughlin, Prog. Mater. Sci. 44 (1999) 291-433.

[2] R.C. O'Handley, Modern magnetic materials, Principles and applications, John Wiley and Sons, New York, 2000.

[3] G. Vlasák, C.F. Conde, D. Janičkovič, P. Švec, J. Magn. Magn. Mater. 304 (2006) 580-582.

[4] J. Rasek, G. Haneczok, Defects Diff. Forum 224225 (2004) 13-26.

[5] A. Chrobak, D. Chrobak, G. Haneczok, P. Kwapuliński, Z. Kwolek, M. Karolus, Mater. Sci. \& Eng. A 382 (2004) 401-406.

[6] H. Szymczak, J. Magn. Magn. Mater. 200 (1999) 425-438.

[7] E. Du Trémolet de Lacheisserie, Magnetostriction: theory and applications of magnetoelasticity, CRC Press Boca Raton, FL, 1993.

[8] E. Du Trémolet de Lacheisserie, J. Magn. Magn. Mater. 25 (1982) 251-270.

[9] Ł. Madej, M. Kubisztal, D. Chrobak, A. Chrobal, G. Haneczok, Inz. Mater. 157-158 (2007) 292-296.

[10] A. Chrobak, G. Haneczok, D. Chrobak, Ł. Madej, G. Chełkowska, M. Kulpa, J. Magn. Magn. Mater. (in press).

[11] Z. Stokłosa, P. Kwapuliński, J. Rasek, G. Badura, G. Haneczok, L. Pająk, L. Lelątko, J. Magn. Magn. Mater. (in press).

[12] P. Kwapuliński, Z. Stokłosa, J. Rasek, G. Badura, G. Haneczok, L. Pająk, L. Lelątko, J. Magn. Magn. Mater. (in press).

[13] G. Vlasák, P. Švec, Z. Kaczkowski, P. Duhaj, Mater. Sci. \& Eng. A 304-306 (2001) 1039-1042.

[14] W.B. Pearson, Crystal chemistry and physics of metals and alloys, Wiley, 1972. 